\title{
Télomères, cancer et sénescence
}

Comment définir le processus du vieillissement ? Faust, avant de vendre son âme au diable, aurait peut-ĉtre tiré bénéfice de la lecture des récents travaux d'une équipe canadienne [1] qui, indirectement, apportent une ébauche de réponse à cette question. Les extrémités de nos chromosomes, les télomères, sont constituées de séquences répétées de 5 à $15 \mathrm{~kb}$, particulièrement conservées au cours de l'évolution et constituants de l'hétérochromatine. La synthèse discontinue de l'ADN d'un des brins lors de la réplication, à partir de petites amorces d'ARN ensuite dégradées, entraîne inéluctablement un raccourcissement des télomères à chaque mitose. Celui-ci ne peut être évité que par la synthèse de novo de télomères sous l'action de la télomérase, une enzyme ribonucléoprotéique qui utilise son ARN interne comme matrice pour la synthèse de répétitions télomériques et est donc dotée d'une activité de transcriptase inverse. Or, différentes observations avaient précédemment montré qu'au cours des divisions cellulaires en culture, donc au cours du vieillissement, les télomères sont progressivement perdus, jusqu'à atteindre une phase dite de " crise " où les cellules cessent de se diviser et meurent. Counter et al. [1] ont tenté d'établir une corrélation entre cette perte progressive des télomères et le processus de sénescence des cellules in vitro. Trois paramètres particuliers ont été étudiés dans deux types cellulaires non transformés et transformés par l'antigène $T$ du virus SV40 ou par un adénovirus de type 5 : (1) la taille de l'ADN télomérique ; (2) l'incidence des chromosomes dicentriques, reflet des fusions chromosomiques dues en partie à la perte des télomères ; (3) l'activité télomérase. Les résultats obtenus montrent que les séquences télomériques sont perdues à un taux équivalent dans les différentes populations et que le pro- cessus continue dans les populations transformées mais non immortalisées. Il en est de même pour l'augmentation de l'incidence des chromosomes dicentriques. Par la suite, la plupart des cellules cessent leurs divisions et seulement un très petit nombre d'entre elles vit à cette étape de crise. Dans deux lignées cellulaires ayant ainsi survécu à la crise, une stabilisation de la taille des séquences télomériques et de la fréquence des chromosomes dicentriques ainsi que l'apparition d'une activité télomérase ont été notées. Si l'acquisition de certains caractères de transformation ne suffit pas à empêcher le raccourcissement des télomères, en revanche l'expression de la télomérase serait un des événements requis pour acquérir l'immortalité. L'hypothèse qui prévalait jusqu'à présent associait la sénescence, et donc la délétion progressive des télomères, à la délétion d'un gène essentiel pour la survie cellulaire. On comprenait cependant mal pourquoi cette étape d'arrêt de la division cellulaire était réversible. W. Wright et J. Shay [2], s'appuyant sur les résultats de l'équipe canadienne et sur d'autres résultats obtenus chez la levure, proposent différentes explications : (a) au cours de la délétion progressive des séquences télomériques, le domaine hétérochromatique pourrait se déplacer et s'étendre aux régions subtélomériques, inactivant ainsi de potentiels répresseurs du programme de sénescence, situés dans ce domaine ; (b) la perte des télomères pourrait également entraîner l'impossibilité pour les chromosomes de s'amarrer à la membrane nucléaire, ou de s'associer à des protéines spécifiques, empêchant alors toute division cellulaire. Lorsque la presque totalité des répétitions est perdue, seule l'activation d'une télomérase permettait d'échapper à cette deuxième étape de mort cellulaire en ajoutant des séquen- ces télomériques. La réversibilité du phénomène est alors beaucoup mieux comprise. Si ce modèle ne nous donne pas encore les clés de la jeunesse éternelle (en effet, il s'agit désormais de mettre en évidence les facteurs régulateurs de la sénescence mentionnés ici), il permet néanmoins de penser que des drogues anti-télomérases pourraient s'avérer être de puissants agents antitumoraux.

H.G.

1. Counter CM, et al. Telomere shortening associated with chromosome instability is arrested in immortal cells which express telomerase activity. $E M B O J 1992 ; 11$ : 1921-9.

2. Wright WE, Shay JS. Telomere positional effects and the regulation of cellular senescence. Trends Genet 1992; 8 : 193-7. 